\title{
Promotion the Personnel Training in Pharmaceutical Engineering field by the High Level Student Competition-Prospects on The First China Student Poster Competition in Pharmaceutical Engineering
}

\author{
Yanfang Li, Hang Song, Xiaojie Ju, Shun Yao, Kaifeng Du, Bing Liang \\ School of Chemical Engineering, Sichuan University, Chengdu, China \\ Email: lyf610065@163.com, Hangsong@vip.sina.com, juxiaojie@scu.edu.cn, Cusack@scu.edu.cn, \\ Kfdu@scu.edu.cn, Liangbing@sina.com
}

Received 2012

\begin{abstract}
In order to better support the development of higher education of Chinese pharmaceutical engineering and encourage the career development of young personnel in Chinese pharmaceutical engineering field, ISPE and Sichuan University jointly organized the first China Student Poster Competition in Pharmaceutical Engineering at the end of August 2011. The academic competition helps to arouse and foster college students' interest and potential, and also attracts enterprises to put forward their technical difficulties and hot points in manufacture. The excellent professional knowledge and sincere voluntary spirit of ISPE members ensure the smooth going of this competition, and increase teachers and students' understanding for ISPE.
\end{abstract}

Keywords: Student Competition; Poster; Personnel Training Pharmaceutical Engineering Education

\section{The Training of Pharmaceutical Engineering Personnel and the Role of the Student Competi- tion}

Since the pharmaceutical engineering major was first set up in 1998, there have been more than 210 universities that set the profession for the undergraduate education, which becomes the fastest-growing major in chemical and pharmaceutical category. However, it is an urgent problem in how to improve the quality of personnel training, promote the student scientific research and innovative thinking, and explore new training mode in the pharmaceutical engineering education.

The academic competition helps to arouse and foster college students' interest and potential, competitive awareness, innovative spirit, practical skill, sense of teamwork, and broaden knowledge, so academic competition has significant importance for comprehensively improving the quality of personnel training. Sichuan University has undertaken the undergraduate innovative research projects for many years, and proved that these projects played a positive role for personnel training of scientific research and innovative thinking. Supported by Ministry of Education and schools, a few universities also started to perform various undergraduates' innovative scientfic research activities. However, the effectiveness of these activities is basically evaluated internally by school, and the lack of mutual communication between universities is mainly due to the limitation of communication platform.

In the area of pharmacy, pharmaceutical group of the National Pharmaceutical Experiment Teaching Demonstration Center organized nationwide Pharmacy / Traditional Chinese Medicine students experiment competition in 2009. In the chemical field, there is a biennial national undergraduate chemistry experiment competition. Both the events achieved favorable results. In this context, there is an urgent need to have a nationwide student competition or platform for pharmaceutical engineering profession to promote the further development of student research activities. In the chemical field, there is a biennial national undergraduate chemistry experiment competition. Both the events achieved beneficial results. In this context, there is an urgent need to have a nationwide student competition or platform for pharmaceutical engineering profession to promote the further development of student research activities.

\section{The First China Student Poster Competition in Pharmaceutical Engineering}

International society for pharmaceutical engineering (ISPE), as the world's largest non-profit organization in pharmaceutical engineering area, has been committed to the training of technical experts, and guides the global technology innovation. So far, ISPE has gathered more than 22,000 professionals from over 100 countries.

Sichuan University is one of the few institutions in the first enrollment of pharmaceutical engineering major in 1999. Over the years, Sichuan University has conducted a series of education researches in pharmaceutical engineering personnel training, the professional curriculum, practical teaching, schoolenterprise cooperation, internationalization and so on, and gradually forms its "Science and engineering integration, practice-oriented, innovative training" school characteristics. On the basis of these achievements, Sichuan University has the opportunity to participate in the 2010 national pharmaceutical engineering characteristic specialty construction project. Among 
domestic colleges, Sichuan University took the lead in establishing cooperative relations with international pharmaceutical engineering association, ISPE, and launched a series of exchange activities, such as establishing the only ISPE student chapter in China, undertaking the translation of the ISPE professional English vocabulary and the "ISPE raw material drug production guidance”. Every year, several ISPE senior industry members give lectures at Sichuan Univerisity. ISPE China office has provided Sichuan university' pharmaceutical engineering students with ISPE technical publications at the value of $\$ 2,000$, funded totally five students attended ISPE China Annual conferences and arranged visits and practices at Chengdu Institute of Biological Products, Chengdu Kanghong Sagent Pharmaceutical, and the Chengdu Rongsheng pharmaceutical company. Two members of the Current ISPE China Council are pharmaceutical engineering professors from Sichuan University and the current chairman of ISPE China Branch of students and youths is a pharmaceutical engineering teacher and two graduates of pharmaceutical engineering from the university served as members in the Branch. The professors and students have played an important role in the ISPE China Council and the subsidiary professional committee. Due to the extensive communications, teachers and students achieved a deeper understanding about the international pharmaceutical industry and the regulatory development.

In order to better support the development of higher education of Chinese pharmaceutical engineering, to encourage the career development of young personnel in Chinese pharmaceutical engineering field, to widely promote the creative thinking and research skills of students majoring in pharmaceutical engineering, to effectively lead the transformation of Chinese pharmaceutical engineering education system, to strengthen the training of the future pharmaceutical engineering professionals, and to promote the process of internationalization of Chinese pharmaceutical industry, ISPE and Sichuan University jointly organized the first China Student Poster Competition in Pharmaceutical Engineering at the end of August 2011. There are 42 students (including undergraduates, masters and doctoral students) from 11 colleges (including Zhejiang University, Tianjin University, Sichuan University, East China University of Science and Technology, South China University of Technology, China Pharmaceutical University, Shenyang Pharmaceutical University, Hefei University of Technology, Wuhan University of Engineering, Zhengzhou University, and Taizhou University) enrolled in this competition. The first, second, third Prize and award of Excellence were decided by 24 domestic and foreign professors and pharmaceutical industry experts through the tele-reviewing and video conferencing review. The first prize winner was funded to participate in the ISPE global annual conference held in Dallas in November 2011.

\section{Inspiration of the First China Pharmaceutical Engineering Student Poster Competition}

\section{Strengthening of the Mechanism for Training Engineering Talents}

The poster competition is open to all students majoring in the field of Pharmaceutical Engineering. The contents include: (1) the application of process analytical techniques in pharmaceutical manufacture; (2) industrial scaling up and optimization for
API manufacture; (3) industrial dosage-form manufacturing process development; pharmaceutical facility design and optimization; (4) application of QbD in process study; (5) the EHS (Environment-Health-Safety) in pharmaceutical manufacture; (6) automation and informationization of pharmaceutical manufacture; (7) studies and applications of the new version GMP and other regulations in pharmaceutical engineering; (8) drug logistics. This competition aims at furthering pharmaceutical and biological engineering students' learning and application of "Unit Operations of Chemical Engineering”, "Chemical Engineering Drawing”, “Chemical Engineering Facilities and Instruments", and so on. Meanwhile, it attempts to encourage the students from the fields of Pharmacy Science, Chemical Engineering, Pharmaceutical Engineering, Mechanics of Engineering and other disciplines to participate. It makes up the shortfall that there is still no domestic professional competition in Pharmacy and Chemistry-related fields and offer students one more opportunity, apart from Chemical Engineering Design Competition, of practical scientific training, foster students`skills of learning, practicing, design and academic writing. Besides keeping freedom of choosing topics, it attracts enterprises to put forward their technical difficulties and hot points in manufacture as innovative topics, thereby to incubate new academic growing points.

\section{Promote Deep Industry-Academia Collaboration}

With the appreciation of the effect of student competitions by students and colleges, various competitions flourish. IndustryAcademia collaboration co-sponsored by national industry associations and colleges and universities' professional teaching of the Steering Committee, has become an essential sustainable fashion for most competitions. It is impossible for pharmaceutical engineering students' competition to expand influence by the large scale as a minor discipline. The only solution is to found a high-level excelsior competition. Suitable engineering talents can be find by incorporations, the "double-quality" teacher groups can be promoted and students, colleges and incorporations both benefit from this competition.

Valuing the Industry-Academia collaboration and gaining incorporations' involvement are not only for financial support, what's more important is to obtain professional technical support, improve competition organization by deriving incorporations' advanced management system, provide a good platform for communications between the incorporations, teachers and students.

\section{Facilitate “Double-Quality” Teaching Forces}

The subject of this competition are student, while the directors are their teachers. For some historical reasons, in most pharmaceutical engineering discipline of domestic higher schools, teaching faculty having pharmacy background lacks related sense of engineering practices, it is requisite to foster and strength multi-disciplinary compound teaching talents.

Teachers, who direct students to take part in foremost competition, should need to renew and enrich their professional knowledge, to improve their own practical professional ability, practical engineering ability. This would hasten the construction of pharmaceutical engineering discipline mode and its maturity. Also, the related colleges and universities obtained a favorable external environment in co-building Engineering 
Practical Education Center in pharmaceutical engineering field, fostering “double-quality” pharmaceutical engineering professsional teacher groups and training international talents with better foreign language skills.

\section{Boost International Collaboration}

Pharmaceutical Engineering Student Poster Competition's preparations has shown that ISPE's support for Chinese colleges and universities' development improves from initial academic and student member enrollment to hosting practical events collaboratively. During the competition, the excellent professional knowledge and sincere voluntary spirit of ISPE members ensure the smooth going of this competition, and increase teachers and students' understanding for ISPE. The collaboration between Academy and industry (internal and external) was further strengthened by intensive communication with ISPE members and the recommendation of veteran experts. More pharmaceutical enterprises could contact and search pharmaceutical engineering students as reserved talents through this platform.

\section{Concluding Remarks}

Pharmaceutical engineering student competition is an important means to foster innovative ability of undergraduate and postgraduate students, which takes positive career development of student as the point. High-level Industry-Academia collaboration would profit students, universities and industry. Therefore, the pharmaceutical engineering student competition would serve and support the global development of China pharmaceutical industry and the education of foremost engineering talents in Chinese universities.

\section{Acknowledgment}

The paper and relative studies were supported by the project on the construction of pharmaceutical engineering feature specialty in Sichuan University which was financed by ministry of education of China (2010-2012).

\section{REFERENCES}

N. N. Ding. On the innovative cultivation approaches of scientific research ability - based pharmacy speciality. Chin. Med. Eth., 2010, 23(3): 50-51

Y. T. Yang. Explore the personnel training methods by combination of college students competition and undergraduate teaching. J. Nanchang College, 2010, (3): 77-79.

X. F. Fu, C. N. Zhang and X. L. Xiao. Advanceing the reform of teaching on practice with opportunity of multifarious competition for undergraduates. Res. Explor. Lab. 2010, 29(1): 127-128.

T. Xie, M. M. Li. Implementation of"goldmedal strategy"in college competition: to explore new modes of talents culturing. Value Eng, 2010, 231-232.

C. H. Tang and J. Zhao. Studies on the way of creative thinking of engineering students- the organization and innovation of college competition. J. Hubei Uni. Econ., 2010, 24(2): 74-75.

J. Z. Chen, Z. Huang and Y. P. Ruan. Experimental skills competition as an opportunity to promote the development of pharmacy experiments teaching. Chin. J. Med. Edu., 2011, (3): 439-441. 